\title{
SOME STATISTICAL PROPERTIES OF MODELS OF TRANSITORY EARNINGS
}

\author{
Miroslava Vlčková1, Tomáš Buus² \\ ${ }^{1}$ Department of Accounting and Finance, Faculty of Economics, University of South Bohemia in České Budějovice, \\ Studentská 13, 37005 České Budějovice, Czech Republic \\ ${ }^{2}$ Department of Corporate Finance and Business Valuation, University of Economics, W. Churchill sq. 4, 13067 \\ Prague, Czech Republic
}

Link to this article: https://doi.org/10.11118/actaun.2021.015

Received: 8. 6. 2020, Accepted: 11. 2. 2021

To cite this article: VLČKOVÁ MIROSLAVA, BUUS TOMÁŠ. 2021. Some Statistical Properties of Models of Transitory Earnings. Acta Universitatis Agriculturae et Silviculturae Mendelianae Brunensis, 69(2): 189-198.

\begin{abstract}
The fact that most of the financial ratios are mean-reverting, is well known. Due to the importance of earnings forecast accuracy, relevant scientific literature in this area concentrates on transitory earnings. The main models used for description of earnings and/or profitability time series are adaptive expectation, autoregressive and partial adjustment models. However, their construction implies severe drawbacks like assumption of intentional adjustment of earnings, sometimes even towards unknown target or towards company-specific target uninfluenced by market, instead of rather realistic assumption of random push of market forces, as we found earlier. This paper proposes a model of mechanical mean reversion of earnings (and/or other company financial data, including ratios). Simulation-based tests of accuracy in a cyclical environment and robustness to input variables non-normality show that the proposed model is more accurate and less biased in capturing the reversion of earnings to industry averages, compared to the most commonly used partial adjustment models.
\end{abstract}

Keywords: accuracy of models, financial expectations, partial adjustment, mean reversion, transitory earnings, normality of residuals

\section{INTRODUCTION}

Some companies could perform extremely well for quite long-time horizons. However, the longterm under- or above-average profitability, which can be attributed to different factors like market anomalies, quality management system, seems to be rather rare. The fact that abnormal earnings are in most cases transitory has been known for long, since already Bliss (1923) suggested that individual firms should have the industry average as a target level of most financial ratios.

The most of estimates of mean reversion (hereinafter MR) of earnings range between 25\% and 50\% p.a. Ewing and Thompson (2007) provide evidence that earnings MR is not symmetrical, and that the corporate profits decreases tend to persist longer (revert less quickly) than increases. However, can a practitioner benefit from the academia findings about earnings MR? The mean reversion of financial ratios can be caused by their oscillation as well (Beaver et al., 2018).

Profitability as a financial ratio is stationary (Ioannidis, Peel and Peel, 2003). Investors at the financial markets seem to know those facts, as share prices deflated by earnings (P/E) are also meanreverting and negatively correlated to profitability. Many of the cited papers also found MR of share prices. That may be related to earnings, resp. profitability MR. Penman (1996) shows that the deflated rates of change in cum-dividend earnings per share converge to approximately the same level 
for each of the 20 portfolios sorted by E/P (earnings per share/price of share). Nevertheless, he shows that profitability measured by book equity-deflated residual income does not converge that much at portfolios sorted by P/B (price of share/book equity per share). If investors believed that profitability converges to some average in long term, then wellperforming companies should have lower P/E, EV/EBIT, etc., and higher share price/equity per share $(\mathrm{P} / \mathrm{BV})$ than their average counterparts, et vice versa, as was observed by Herrmann and Richter (2003). They found out that valuation multiples and profitability ratios are mean-reverting.

Despite the detailed research on analysts' earnings expectations, there is little evidence on direct (implied) investors' expectations about the profit MR.

Also, the up-to-date findings do not provide accurate models for forecasting of transitory earnings, as at least stock market bubbles and crashes prove. The main models used for description of earnings and/or profitability time series are autoregressive (hereinafter AR) and partial adjustment (hereinafter PA) models, the latter of which are frequently mismatched with models of adaptive expectation. The formulation of AR models in the literature on transitory earnings implies that the targets are company-specific in case of AR models (regardless of the usual profitability in the industry). Recent PA models imply that there is intentional adjustment of profits at the examined company, towards the last industry average or towards future unknown target, which would be both nonsenses, especially for the superior companies. Some of the models used for the examination of transitory earnings (e.g. Fama and French, 2000) are designed in a way that one does not know what converges - is it the expectations of future profits or profits themselves? However, Arendas and Chovancova (2015) state that the ability of share prices to reflect all the available information changes over time. Distribution of financial ratios is also an issue as it mostly does not seem to follow a normal distribution.

Therefore, the aim of this paper is to propose equation of mean reversion (hereinafter MR) of expected earnings in its first part. We derive the cited equation from the decomposition of market multiplier (e.g. P/E) to its permanent and transitory components.

The second aim of this paper is to describe the peculiarities of the earnings transition measurement - nonnormally distributed financial ratios and their consequences for ordinary least squares (OLS) residuals, methods of data transformation, and properties of different earnings measures.

Subsequently, we derive an optimal statistical model of MR of earnings and test it via simulation against PA and AR models.

\section{MATERIALS AND METHODS}

\section{Methodological Issues of Transitory Earnings Research}

There are four main methodological issues in literature on MR of earnings, which have not been discussed in sufficient detail.

First, both recent and older papers use almost exclusively PA models and AR or autocorrelation (AC) models to measure earnings MR. There are difficulties to interpreting both of them.

$\mathrm{AR}$ and $\mathrm{AC}$ model estimates on historical data generally assume company-specific targets (Tong, 2011). Unsurprisingly, Dechow et al. (1999) find approximately the same autocorrelation function value of net income per share as Beaver (1970) did with AR (Dechow's 38\% compared to Beaver's 32\%). Due to AR coefficient, we see that earnings revert to the mean, but do not converge. Unfortunately, neither AR nor AC models tell us where the target is and we can get the same estimates for both growing and decreasing profits (or profitabilities) (Vlčková and Buus, 2019).

Both PA and AC/AR models mix company-specific and industry- or economy-wide factors, if used the way they were used for earnings MR measurement. However, if one of the primary earnings MR uses is valuation (pricing) of businesses and shares via comparison to peers (Demirakos et al., 2004), then markets are surely interested in finding how the actual relative advantage or disadvantage of a particular company compared to peers influences share prices and what earnings MR rate can they expect.

Second, due to inflation (in the meaning of price level change) as well as due to different sizes of companies on the stock market, there is a need to deflate profits and stock prices. Improper choice of the deflator can cause a plethora of problems from fat tails to skewed distribution and overweighting of some subsets of the data samples.

Third, data are tricky. Not only is there a need to deflate the earnings, assets, and/or share prices so that inflation and company size does not affect the results, but also accounting ratios and earnings generally do not have the normal distribution.

Fourth, some of the parts of the earnings are irrelevant for the forecasting of future profits. Accruals are a typical example, although share prices react to them.

\section{Model of Expected Earnings Mean Reversion}

Gropp (2004) proposes MR model, which differs from PA and AR models. PA models implicitly assume intentional adjustment towards future unknown or last know industry average. AR models assume adjustment towards companyspecific unknown target. MR models do not suffer from these assumptions. That fits the possibility of mechanical (random) earnings MR. The main 
assumptions of the subsequently proposed pure MR model (above the common ones) are:

- the target of earnings is industry-specified peer group average, as the industry pertinence explains part of future earnings (e.g. Lev, 1969),

- there is a long-term average growth rate $g^{*}$ common to all peer-group members' normalized financials, e.g. earnings $x^{*}$, sales, assets, or equity. Normalization means that the variable is proportional at the industry average (e.g. profitability) to the size of the company.

Normalization means that the variable is proportional at the industry average (e.g. profitability) to the size of the company, thus $e^{*}$ represents earnings, which the particular company would reach under normal (permanently achievable) profitability. Earnings can be at level of EBIT, EBT or EAT. If earnings $x$ of particular company differ from the "normal" ones $X^{*}$, i.e. $x \neq X^{*}$, then there is non-zero abnormal profit

$X^{A}=X-X^{*}$

in the case that $x^{A} \neq 0$. Abnormal earnings $x^{A}$ grow by abnormal growth rate - $\alpha$; $\alpha \geq 0$ besides the normal one $\left(g^{*}\right)$, so that

$X_{t+1}^{*}=X_{t}^{*}\left(1+g^{*}\right)$

and

$X_{t+1}^{A}=X_{t}^{A}(1-\alpha)\left(1+g^{*}\right)$,

where $t$ represents discrete time.

\section{Deflator for Model of MR of Earnings}

Profit expectations are not stationary. Profits tend to grow on the average. Therefore, the use of a deflator can eliminate the heteroskedasticity of valuation errors (Ball et al., 2015). Beatty, Riffe and Thomson (1999) found the weighted harmonic mean to be a superior estimates of industry average market financial ratios (e.g. P/E, P/BV, EV/EBIT, $\mathrm{EV} /$ Sales).

Most of the papers, which look into transitory financials, deflate them. The deflating variables are mostly assets or BV so that the ratio turns out to be ROA with earnings after or before tax (e.g. Lev, 1969; Fama and French, 2000). Other researchers analysed net income/assets (e.g. Frecka and Lee (1986) or return on investment (ROI), e.g. Konings and Roodhooft (1997)). Because most of the variables in financial statements are proportional to the company size, there is a cointegration between ratio variables. Thus, financial ratios are stationary.

Variance of any ratio, where the profit is a numerator, can be higher or lower than the variance of profit, depending mostly on the variance and mean of both the divisor and numerator. The denominator and numerator consistence is important for the usability of MR research results in valuation models, which are indeed besides the earnings management research, the main reason for looking into transitory financials (financial ratios). The measure satisfying both requirements - stability and consistence - is earnings deflated by the normalized earnings. However, we do not claim exclusivity of this ratio with respect to the stability and consistence - invested capital (ROIC) or more simply return on capital (ROC) could be applicable too. ROC and ROIC have been seldom tested for MR in scientific papers (Vlčková and Buus, 2018). The relevant papers also seldom measure margins MR, although margins (ratio of earnings to sales) are a significant tool in financial forecasting.

Because $X_{t+1}^{A}=\left(x_{t+1}-x_{t+1}^{*}\right)$ and we can divide both sides of (3) by $x_{t+1}^{*}$, by that decomposition and deflation we obtain equation of the adjustment process (or expectation of adjustment process) of deflated $e^{A}$

$\frac{\left(X_{t+1}-X_{t+1}^{*}\right)}{X_{t+1}^{*}}=\frac{(1-\alpha)\left(X_{t}-X_{t}^{*}\right)}{X_{t}^{*}}$.

Equation (4) can be used for estimation of MR expectations and formulation of statistical model of expected rate of growth of abnormal earnings, i.e. rate of mean reversion $(-\alpha)$.

Also, equations (1) to (4) can be used for modification of Gordon's (1959, p. 103) income valuation model (which is based on the sum of the infinite geometric series) under practically acceptable assumption that the cost of capital are constant through time (Qi, 2011).

\section{Models Subject to Test Via Simulation}

We want to find out whether the pure MR models are superior to PA and AR models in terms of accuracy and usefulness for forecasting. First, we need to put our model (4) to the test.

There are two basic specification of PA models, historically used for transitory earnings.

First one is with the expected value as a target (Lev, 1969, p. 292)

$x_{t}-x_{t-1}=\beta\left(x_{t}^{*}-x_{t-1}\right)$.

The second one has the last known target as the actual one (Waud, 1968, p. 205)

$x_{t}-x_{t-1}=\beta\left(x_{t-1}^{*}-x_{t-1}\right)$.

Coefficient $\beta$ can be significant even with constant $x_{t}-x_{t-1}$ or $x_{t}^{*}-x_{t}$ resp. $x_{t}^{*}-x_{t-1}$ (no convergence). Assume that in equation (6) all $x$ are deflated as well as in equation (5). To study the company-specific part of MR, let us rearrange equation (4) and assume deflated $x$ :

$x_{t}-x_{t}^{*}=\beta\left(x_{t-1}-x_{t-1}^{*}\right)$.

Thus, the meaning of $\beta$ in (7) is similar as 1 - $a$ has in equation (4). Equation (7) is formulated similarly to the one in Gropp (2004). Equation (7) does not 
imply an intentional adjustment to the last known optimum, nor to the expected (or maybe known) optimum. It rather assumes an unintentional stochastic MR, which courses due to the nature of the underlying process, e.g. competition in industry.

Use of PA model is justifiable for the assessment of capital structure policy, because it can be intentionally influenced by management much easier than profitability.

The other models of transitory earnings to compare to (5), (6) and (7), are AR(1) of $x / x^{*}$, introduced for transitory earnings by Beaver (1970) and used and/or extended by Dechow et al. (1999), Frankel and Litov (2009), Dichev and Tang (2009), Fairfield et al. (2009), Goddard et al. (2005) and many others. AR(1) of $x / x^{*}$ equals $\operatorname{ACF}(1)$ of $x / x^{*}$ as $\sigma_{x / x_{t}^{*}}=\sigma_{x / x_{t-1}}$ :

$x_{t}=\beta x_{t-1}$.

Many of the mentioned papers, which try to explain transitory earnings via ACF, resp. AR models, examine deflated earnings. However, their deflating variables (like book or market value of capital) are not necessarily proportional to the deflated earnings. Therefore, we do not deflate earnings in (8).

The benchmark to the above models is the ex-post one-period observed MR rate

$\alpha_{\text {real }}=1-\frac{\left(x_{t}^{A} / X_{t}^{*}\right)}{\left(x_{t-1}^{A} / x_{t-1}^{*}\right)}$.

\section{RESULTS AND DISCUSSION}

\section{Simulation}

Let us compare accuracy of models defined by equations (5), (6), (7), AR(1) of $x / x^{*}$ and ex-post observed MR rate

$$
\alpha_{\text {real }}=1-\frac{\left(x_{t}^{A} / x_{t}^{*}\right)}{\left(x_{t-1}^{A} / x_{t-1}^{*}\right)}
$$

in explaining industry data, where there are three subjects with equal share on the relevant variable (e.g. earnings) in the relevant peer group (e.g. industry), the data are generated by cyclical processes (cyclical component $c_{t}=10 \sin (t / 2)$ ) or non-cyclical processes with random error $\varepsilon_{t} \sim \mathrm{N}[0 ; 14]$ and MR, resp. PA, resp. AR transitory component $m_{t}$

- G1: AR(1) specification with error term means that $x_{t}=\beta x_{t-1}+\varepsilon_{t}$. In order to include the cyclical term, let us rearrange the AR(1) specification to $X_{t}^{A}=\beta X_{t-1}^{A}+\varepsilon_{t}$, so that if $X_{t}^{*} \equiv c_{t}$ and because $X_{t-1}^{A} \equiv \varepsilon_{t-1}$ then $x_{t}=c_{t}+\beta \varepsilon_{t-1}+\varepsilon_{t}$.

- G2 MR: If $x_{t}^{*} \equiv c_{t}$ and equation (7) defines $x_{t}$ then $x_{t}=c_{t}+\beta\left(x_{t-1}-x_{t-1}^{*}\right)+\varepsilon_{t}$.

- G3 PA (Lev, 1969): If $x_{t}^{*} \equiv c_{t}$ and equation (6) defines $x_{t}$ then by deduction of $x_{t}^{*} \equiv c_{t}$ from both sides of equation (6) and adding $\varepsilon_{t}$ we get $x_{t}=c_{t}+(1-\beta)\left(x_{t-1}-c_{t}\right)+\varepsilon_{t}$.

- G4 PA (Waud, 1968): If $x_{t}^{*} \equiv c_{t}$ and equation (5) defines $x_{t}$ then by deduction of $x_{t-1}^{*}$ from both sides of equation (5) and adding $\varepsilon_{t}$ we get $x_{t}=x_{t-1}^{*}+(1-\beta)\left(x_{t-1}-x_{t-1}^{*}\right)+\varepsilon_{t}$.

We tested 6 scenarios: Four were created by combination of $\beta=0.2$, resp. $\beta=0.8$ with $c_{t}=10 \sin (t / 2)$ (existing cycle), resp. $c_{t}=1$ (no cycle). Fifth and sixth scenario is $c_{t}=20$ and $\beta=0.2$, resp. $\beta=0.8$ to compare to S3 and S4 results under different shares of $m_{t}$ and $c_{t}$ on $x_{t}$. Therefore, the scenarios are:

- $\mathrm{S} 1: \beta=0.8, c_{t}=10 \sin (t / 2)$.

- $\mathrm{S} 2: \beta=0.2, c_{t}=10 \sin (t / 2)$.

- S3: $\beta=0.8, c_{t}=1$.

- $S 4: \beta=0.2, c_{t}=1$.

- S5: $\beta=0.8, c_{t}=20$.

- S6: $\beta=0.2, c_{t}=20$.

The below results of ordinary least squares (OLS) estimates of $\beta$ in equations (5), (6), (7), AR(1) of $x / x^{*}$ and ex-post observed MR rate are based on 100 simulations, each containing 100-period time series. The cycle length is 12 periods if the cycle is present. The "normal" $x_{t}^{*}$ is weighted average of individual ones, with weights equal to shares on industry.

Figs. 1-6 provide an example of G1 to G4 simulation outputs. G3 it does not reproduce cycles well under low MR because its form almost eliminates the cyclical component. G4 quite frequently generates systematically growing or decreasing $x_{t}$ despite reflecting the cyclical component well. G2 can generate long-term above- or underperformance as well as G4, but it does not generate long-term increasing or decreasing results, compared to G4.

Estimated $\hat{\beta}$ in PA equation (5) (Lev, 1969) and equation (6) (Waud, 1968) move in the opposite way to $\hat{\beta}$ in MR equation (7). That is in line with the specification of the models. Lev's (1969) PA (with a priori knowledge of the future optimal target) overestimates the adjustment speed $(\hat{\beta})$ mostly in the case of slow adjustments or high MR.

AR (1) models do not enable to distinguish between cyclical and abnormal (random) component of the earnings. That holds especially for the earnings deflated by industry average. Also, they are not good at assessing reversion to industry average, in line with their specification (where the target is de facto company specific).

Waud's (1968) PA estimates $\hat{\beta}$ perform similarly to pure MR (7) at all generating processes, and are superior to other models of transitory earnings.

\section{Distribution of Financials and Their Ratios vs. Transitory Earnings Models}

Generally, there is a conclusion in the literature that the normal distribution of financial ratios is a rather scarce case (Boldin and Petriev, 2018). Unfortunately, 
G1 (AR) - scenario S1

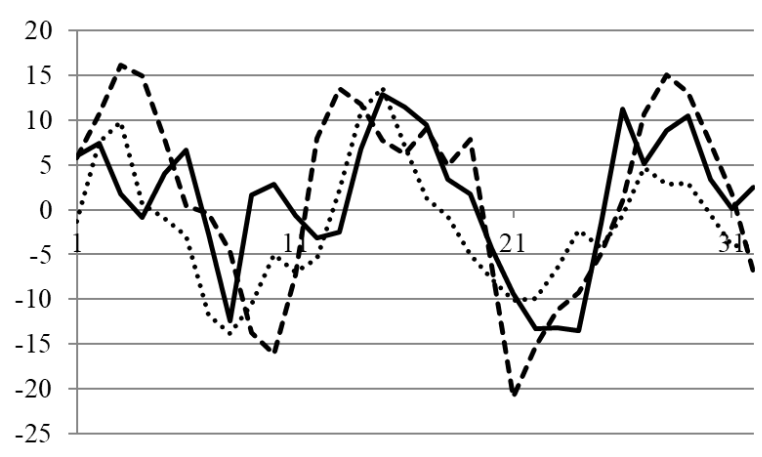

G2 (MR) - scenario S1

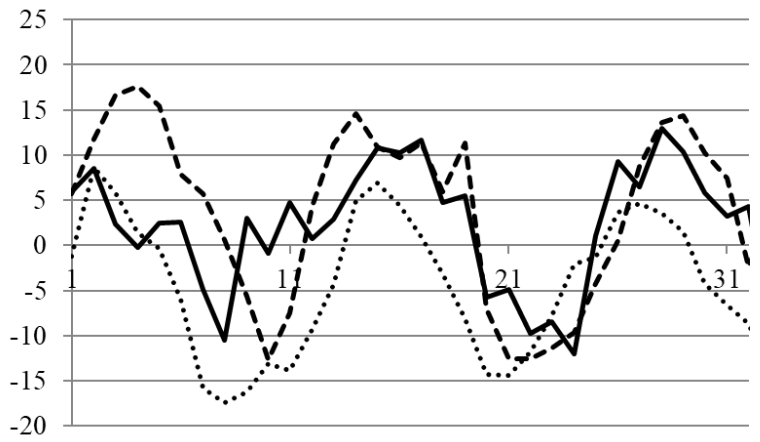

G3 - PA (Lev, 1969) - scenario S1

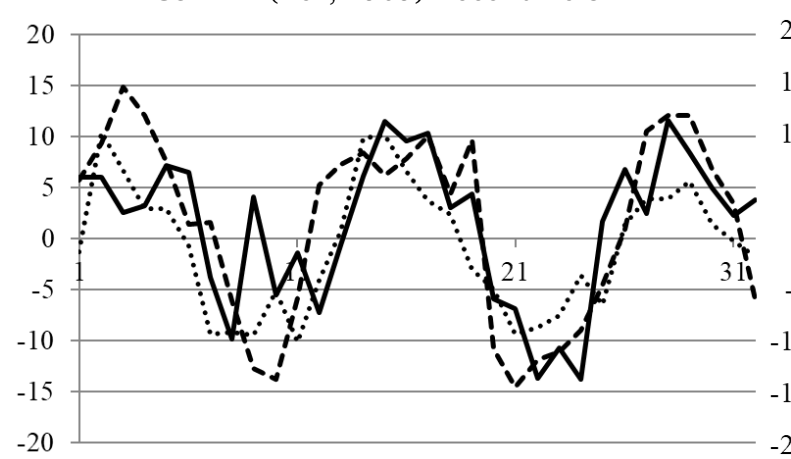

G4 - PA (Waud, 1968) - scenario S1

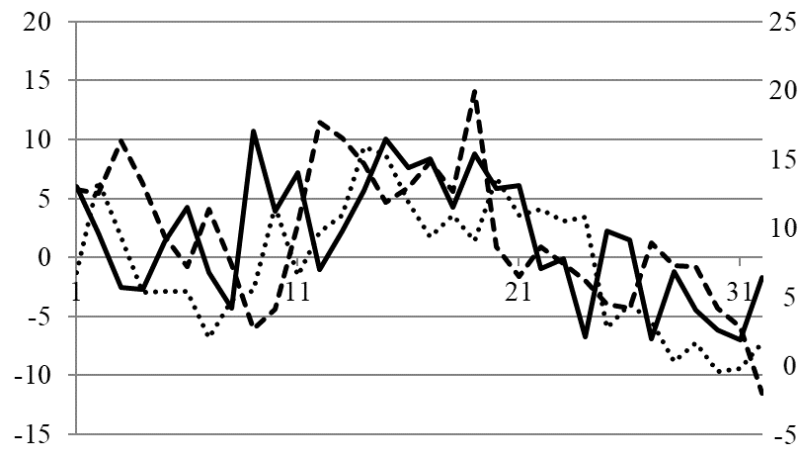

G1 (AR) - scenario S2

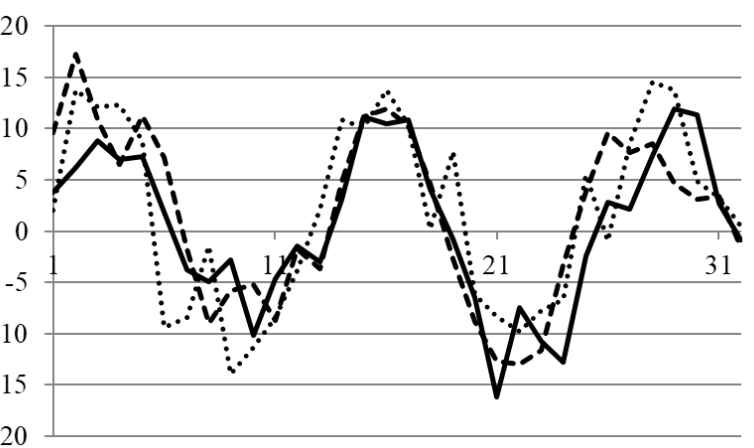

G2 (MR) - scenario S2

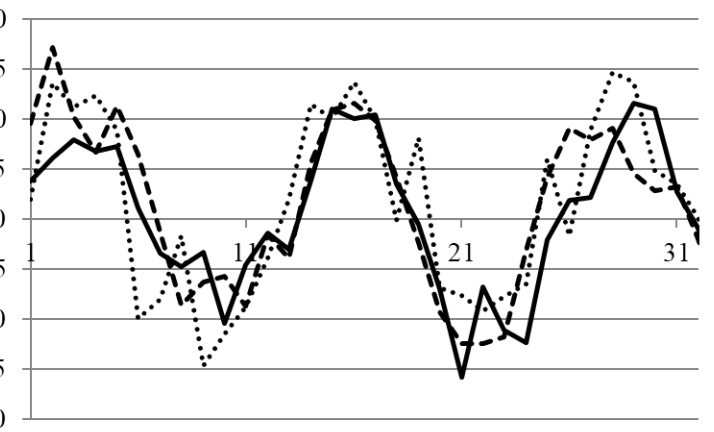

G3 - PA (Lev, 1969) - scenario S2

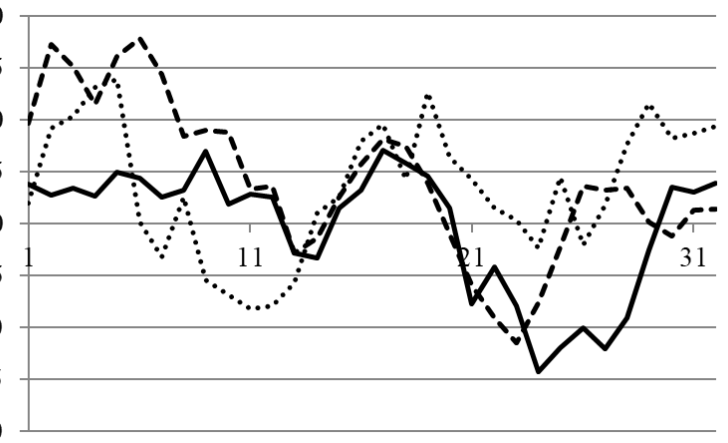

G4 - PA (Waud, 1968) - scenario S2

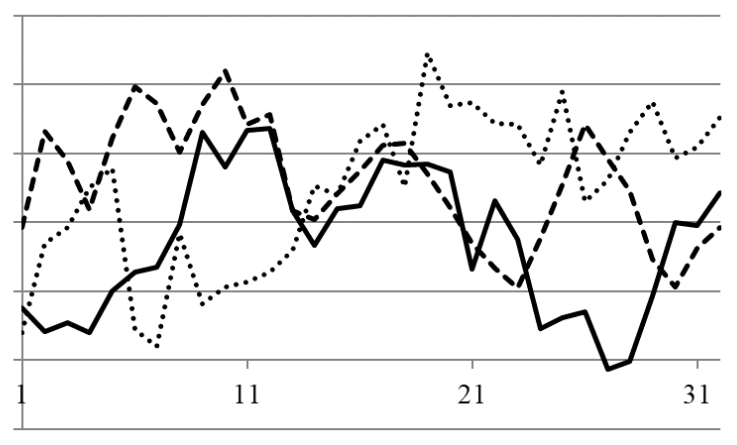

1-8: Example of $x_{t}$ of the 3 companies in 32-period time series in simulation under scenarios $S 1$ and S2 and with generating processes G1-G4

Descriptions of axis: $\mathrm{x}$-axis - 32 period time series; $\mathrm{y}$-axis: range Source: own research 
I: Accuracy of models of transitory earnings

\begin{tabular}{|c|c|c|c|c|c|c|}
\hline & $x \operatorname{ACF}(1)$ & $x / x^{*} \mathrm{ACF}(1)$ & $\tilde{a}_{\text {real }}$ & $\hat{\beta}$ in $(5)(L e v, 1969)$ & $\hat{\beta}$ in (6) (Waud, 1968) & $\hat{\beta}$ in $(7)(\mathrm{MR})$ \\
\hline \multicolumn{7}{|c|}{$\mathrm{S} 1: \beta=0.8, c_{t}=10 \sin (t / 2)$} \\
\hline \multirow{2}{*}{ G1 } & 0.758 & 0.015 & 0.732 & $0.791[0.2]$ & $0.512[0.2]$ & $0.488[0.8]$ \\
\hline & $(0.019)$ & $(0.068)$ & $(0.073)$ & $(0.033)$ & $(0.043)$ & $(0.043)$ \\
\hline \multirow{2}{*}{ G2 } & 0.804 & -0.007 & 0.463 & $0.575[0.2]$ & $0.205[0.2]$ & $0.795[0.8]$ \\
\hline & $(0.017)$ & $(0.233)$ & $(0.082)$ & $(0.063)$ & $(0.038)$ & $(0.038)$ \\
\hline \multirow{2}{*}{ G3 } & 0.722 & 0.000 & 0.897 & $0.932[0.8]$ & $0.798[0.8]$ & $0.202[0.2]$ \\
\hline & $(0.022)$ & $(0.059)$ & $(0.065)$ & $(0.024)$ & $(0.060)$ & $(0.060)$ \\
\hline \multirow{2}{*}{ G4 } & 0.815 & 0.044 & 0.821 & $0.862[0.8]$ & $0.797[0.8]$ & $0.203[0.2]$ \\
\hline & $(0.103)$ & $(0.135)$ & $(0.088)$ & $(0.045)$ & $(0.062)$ & $(0.062)$ \\
\hline \multicolumn{7}{|c|}{$\mathrm{S} 2: \beta=0.2, c_{t}=10 \sin (t / 2)$} \\
\hline \multirow{2}{*}{ G1 } & 0.729 & -0.001 & 0.922 & $0.936[0.8]$ & $0.804[0.8]$ & $0.196[0.2]$ \\
\hline & $(0.022)$ & $(0.059)$ & $(0.063)$ & $(0.024)$ & $(0.068)$ & $(0.068)$ \\
\hline \multirow{2}{*}{ G2 } & 0.718 & 0.000 & 0.924 & $0.937[0.8]$ & $0.797[0.8]$ & $0.203[0.2]$ \\
\hline & $(0.023)$ & $(0.059)$ & $(0.066)$ & $(0.024)$ & $(0.070)$ & $(0.070)$ \\
\hline \multirow{2}{*}{ G3 } & 0.816 & 0.013 & 0.475 & $0.383[0.2]$ & $0.205[0.2]$ & $0.795[0.8]$ \\
\hline & $(0.030)$ & $(0.076)$ & $(0.108)$ & $(0.066)$ & $(0.047)$ & $(0.047)$ \\
\hline \multirow{2}{*}{ G4 } & 0.902 & 0.215 & 0.265 & $0.330[0.2]$ & $0.205[0.2]$ & $0.795[0.8]$ \\
\hline & $(0.043)$ & $(0.329)$ & $(0.088)$ & $(0.062)$ & $(0.047)$ & $(0.047)$ \\
\hline \multicolumn{7}{|c|}{ S3: $\beta=0.8, c_{t}=1$ (no cycle) } \\
\hline \multirow{2}{*}{ G1 } & 0.485 & -0.009 & 0.871 & $0.674[0.2]$ & $0.515[0.2]$ & $0.485[0.8]$ \\
\hline & $(0.042)$ & $(0.067)$ & $(0.081)$ & $(0.045)$ & (0.048) & (0.048) \\
\hline \multirow{2}{*}{ G2 } & 0.666 & 0.007 & 0.900 & $0.422[0.2]$ & $0.209[0.2]$ & $0.791[0.8]$ \\
\hline & $(0.062)$ & $(0.047)$ & $(0.082)$ & $(0.068)$ & $(0.043)$ & $(0.043)$ \\
\hline \multirow{2}{*}{ G3 } & 0.194 & -0.007 & 0.968 & $0.888[0.8]$ & $0.802[0.8]$ & $0.198[0.2]$ \\
\hline & $(0.055)$ & $(0.062)$ & $(0.056)$ & $(0.040)$ & $(0.065)$ & $(0.065)$ \\
\hline \multirow{2}{*}{ G4 } & 0.810 & 0.032 & 0.860 & $0.864[0.8]$ & $0.802[0.8]$ & $0.198[0.2]$ \\
\hline & $(0.105)$ & $(0.112)$ & $(0.081)$ & $(0.047)$ & $(0.065)$ & $(0.065)$ \\
\hline \multicolumn{7}{|c|}{ S4: $\beta=0.2, c_{t}=1$ (no cycle) } \\
\hline \multirow{2}{*}{ G1 } & 0.192 & -0.004 & 0.972 & $0.892[0.8]$ & $0.804[0.8]$ & $0.196[0.2]$ \\
\hline & $(0.056)$ & $(0.045)$ & $(0.053)$ & $(0.043)$ & $(0.074)$ & $(0.074)$ \\
\hline \multirow{2}{*}{ G2 } & 0.136 & 0.001 & 0.984 & $0.895[0.8]$ & $0.796[0.8]$ & $0.204[0.2]$ \\
\hline & $(0.060)$ & $(0.036)$ & $(0.048)$ & $(0.041)$ & $(0.076)$ & $(0.076)$ \\
\hline \multirow{2}{*}{ G3 } & 0.792 & 0.034 & 0.487 & $0.336[0.2]$ & $0.200[0.2]$ & $0.800[0.8]$ \\
\hline & $(0.035)$ & $(0.090)$ & $(0.107)$ & $(0.058)$ & $(0.044)$ & $(0.044)$ \\
\hline \multirow{2}{*}{ G4 } & 0.905 & 0.103 & 0.290 & $0.323[0.2]$ & $0.200[0.2]$ & $0.800[0.8]$ \\
\hline & $(0.047)$ & $(0.235)$ & $(0.086)$ & $(0.057)$ & $(0.044)$ & $(0.044)$ \\
\hline \multicolumn{7}{|c|}{ S5: $\beta=0.8, c_{t}=20$ (no cycle) } \\
\hline \multirow{2}{*}{ G1 } & 0.475 & 0.470 & 0.521 & $0.688[0.2]$ & $0.522[0.2]$ & $0.478[0.8]$ \\
\hline & $(0.037)$ & $(0.050)$ & $(0.073)$ & $(0.045)$ & $(0.051)$ & $(0.051)$ \\
\hline \multirow{2}{*}{ G2 } & 0.658 & 0.771 & 0.210 & $0.432[0.2]$ & $0.213[0.2]$ & $0.787[0.8]$ \\
\hline & $(0.062)$ & $(0.051)$ & $(0.062)$ & (0.068) & $(0.047)$ & $(0.047)$ \\
\hline
\end{tabular}




\begin{tabular}{|c|c|c|c|c|c|c|}
\hline & $x \operatorname{ACF}(1)$ & $x / x^{*} \operatorname{ACF}(1)$ & $\tilde{\mathrm{a}}_{\text {real }}$ & $\hat{\beta}$ in $(5)(\mathrm{Lev}, 1969)$ & $\hat{\beta}$ in (6) (Waud, 1968) & $\hat{\beta}$ in $(7)(M R)$ \\
\hline \multirow{2}{*}{ G3 } & 0.186 & 0.183 & 0.808 & $0.897[0.8]$ & $0.813[0.8]$ & $0.187[0.2]$ \\
\hline & $(0.055)$ & $(0.074)$ & $(0.090)$ & $(0.043)$ & $(0.075)$ & $(0.075)$ \\
\hline \multirow{2}{*}{ G4 } & 0.811 & 0.150 & 0.821 & $0.873[0.8]$ & $0.813[0.8]$ & $0.187[0.2]$ \\
\hline & $(0.112)$ & $(0.128)$ & $(0.089)$ & $(0.052)$ & $(0.075)$ & $(0.075)$ \\
\hline \multicolumn{7}{|c|}{ S6: $\beta=0.2, c_{t}=20$ (no cycle) } \\
\hline \multirow{2}{*}{ G1 } & 0.192 & 0.195 & 0.798 & $0.889[0.8]$ & $0.800[0.8]$ & $0.200[0.2]$ \\
\hline & $(0.052)$ & $(0.065)$ & $(0.083)$ & $(0.037)$ & $(0.063)$ & $(0.063)$ \\
\hline \multirow{2}{*}{ G2 } & 0.137 & 0.202 & 0.793 & $0.893[0.8]$ & $0.792[0.8]$ & $0.208[0.2]$ \\
\hline & $(0.056)$ & $(0.067)$ & $(0.088)$ & $(0.037)$ & $(0.066)$ & $(0.066)$ \\
\hline \multirow{2}{*}{ G3 } & 0.789 & 0.779 & 0.202 & $0.338[0.2]$ & $0.203[0.2]$ & $0.797[0.8]$ \\
\hline & $(0.038)$ & $(0.108)$ & $(0.061)$ & $(0.061)$ & $(0.046)$ & $(0.046)$ \\
\hline \multirow{2}{*}{ G4 } & 0.893 & 0.579 & 0.217 & $0.325[0.2]$ & $0.203[0.2]$ & $0.797[0.8]$ \\
\hline & $(0.052)$ & $(0.339)$ & $(0.076)$ & $(0.060)$ & $(0.046)$ & $(0.046)$ \\
\hline \multicolumn{4}{|c|}{ Mean error of $\hat{\beta}$ estimates G1-G4; S1-S6 } & 0.182 & 0.042 & -0.042 \\
\hline \multicolumn{4}{|c|}{ MAE G1-G4; S1-S5 } & 0.182 & 0.044 & 0.044 \\
\hline \multicolumn{4}{|c|}{ Mean error of $\hat{\beta}$ estimates G2-G4; S1-S6 } & 0.139 & 0.003 & -0.003 \\
\hline \multicolumn{4}{|c|}{ MAE G2-G4; S1-S6 } & 0.139 & 0.005 & 0.005 \\
\hline
\end{tabular}

Average OLS estimates of $\beta$ in equations (5), (6), (7). Average is from 100 estimates of $\beta$ for 100-period time series generated by G1, G2, G3, G4 processes under scenarios S1-S5 (see above). Standard deviations of $\beta$ in 100 simulations are in parentheses. Expected value of $\beta$ in brackets are adjusted for the type of process. $\tilde{a}_{\text {real }}$ is median of $\alpha_{\text {real }}$; Errors are computed across all simulations (S1-S5) and all generating processes (G1-G4) based on $\hat{\beta}$ less expected $\beta$.

Source: own research

we do not know much about residuals. If we assumed that the financial ratios are autocorrelated, then their distributions would have to be the same in subsequent periods. Thus, in the simple AR Equation (1) model, the regression coefficient equals ACF Equation (1). The other consequence of i.i.d. residuals is that they need to have a distribution similar to the distribution of the autocorrelated variable. Without being too unrealistic, we can say that financial ratios or deflated financials are generated by stationary processes. Non-normally distributed $x_{t}$ highly probably lead to non-normally distributed differences $x_{t}-X_{t}^{*}$

As one goes further into more complicated models (namely PA models), it becomes more difficult to get any theoretical inference about error term distribution from distribution of the earnings time series $X_{t}$. Let us utilize the simulation again. The 100 times generated 1000 observations of variables $x_{t}=i^{2} ; i \sim N[0 ; 1] ; x_{t}^{*}=E\left(x_{t}\right)$ provide the evidence. The simulation was not complicated with cyclical or constant component, because just the random term matters for the residuals. Let us use the same denotation of residuals and error term (or in other words, let us assume that the above models are the true ones to describe the random data) for simplicity. Comparison of residuals (errors) from Equations (5), (6), (7), and simple AR Equation (1) shows the following Tab. II. Residuals are defined as follows:
- $\mathrm{AR}:=x_{t}-\beta x_{t-1}$,

- PA (Lev, 1969): = $\left(x_{t}-x_{t-1}\right)-\beta\left(x_{t}^{*}-x_{t-1}\right)$,

- PA (Waud, 1968): $=\left(x_{t}-x_{t-1}\right)-\beta\left(x_{t-1}^{*}-x_{t-1}\right)$,

- pure MR: $=\left(x_{t}-x_{t}^{*}\right)-\beta\left(x_{t-1}-x_{t-1}^{*}\right)$.

We could get similar conclusions about kurtosis - leptokurtic distribution of $x_{0, t}=i^{3} ; i \sim N[0 ; 1]$ should theoretically lead to leptokurtic AR Equation (1) residuals and $\varepsilon_{(14)}$. Again, the inferences for Lev's (1969) and Waud's (1968) PA models are better to be found by simulation. Simulation results are in Tab. III.

Through similar simulation we find that normal $x_{t}=i ; i \sim N[0 ; 1]$ means no significant skewness and kurtosis in the case of residuals.

Simulation results show that the skewness and kurtosis of residuals tend towards normality with increasing AR Equation (1) coefficient in that model. Thus, one cannot rely on AR model if the autocorrelated variable is not normal. The same holds for Lev's (1969) PA model Equation (5) with respect to skewness and for Waud's (1968) PA model Equation (6) with respect to kurtosis. Lev's (1969) PA model and pure MR model Equation (7) are able to somehow filter out the skewness. Nevertheless, pure MR residuals skewness is also sensitive to the skewness of input variables, although much less than Lev's (1969) PA model. In the case of low MR of the examined variable, the Waud's (1968) and pure MR models can provide unbiassed (or very little biassed) estimates with respect to skewness. With 
II: Skewness of transitory earnings models residuals if $x_{0, t}=i^{2} ; i \sim N[0 ; 1]$

\begin{tabular}{|c|c|c|c|c|c|c|c|c|c|c|}
\hline \multirow{2}{*}{$\begin{array}{l}x_{0, t}=i^{2} \\
i \sim N[0 ; 1]\end{array}$} & \multicolumn{5}{|c|}{ Number of averaged observations in $x_{t}^{*} .5$} & \multicolumn{5}{|c|}{ Number of averaged observations in $x_{t}^{*}: 10$} \\
\hline & $x_{0, t}$ & $\varepsilon_{(\mathrm{AR})}$ & $\varepsilon_{(5)}$ & $\varepsilon_{(6)}$ & $\varepsilon_{(7)}$ & $x_{0, t}$ & $\varepsilon_{(\mathrm{AR})}$ & $\varepsilon_{(5)}$ & $\varepsilon_{(6)}$ & $\varepsilon_{(7)}$ \\
\hline \multirow{2}{*}{$\beta=0$} & 2.554 & 2.554 & 0.009 & -0.127 & 0.009 & 2.631 & 2.631 & -0.011 & -0.291 & -0.011 \\
\hline & $(0.063)$ & $(0.064)$ & $(0.022)$ & $(0.163)$ & $(0.022)$ & $(0.083)$ & $(0.083)$ & $(0.022)$ & $(0.328)$ & $(0.022)$ \\
\hline \multirow{2}{*}{$\beta=0.25$} & 2.573 & 2.312 & 0.458 & -0.101 & -0.141 & 2.613 & 2.345 & 0.612 & 0.028 & -0.079 \\
\hline & $(0.073)$ & $(0.064)$ & $(0.022)$ & $(0.264)$ & $(0.020)$ & $(0.063)$ & $(0.056)$ & $(0.026)$ & $(0.080)$ & $(0.024)$ \\
\hline \multirow{2}{*}{$\beta=0.5$} & 2.588 & 1.604 & 0.988 & -0.018 & -0.296 & 2.597 & 1.621 & 1.317 & 0.005 & -0.151 \\
\hline & $(0.065)$ & $(0.044)$ & $(0.034)$ & $(0.190)$ & $(0.025)$ & $(0.074)$ & $(0.051)$ & $(0.044)$ & $(0.122)$ & $(0.027)$ \\
\hline \multirow{2}{*}{$\beta=0.75$} & 2.579 & 0.772 & 1.517 & 0.050 & -0.429 & 2.620 & 0.764 & 1.942 & -0.013 & -0.229 \\
\hline & $(0.063)$ & $(0.028)$ & $(0.042)$ & $(0.196)$ & $(0.026)$ & $(0.080)$ & $(0.032)$ & $(0.059)$ & $(0.072)$ & $(0.026)$ \\
\hline
\end{tabular}

Average skewness of 100 times 1000-period time series of $x_{t}=i^{2} ; i \sim N[0 ; 1]$. Standard deviation of the 100 skewnesses (100 simulations) in parentheses.

Source: own research

III: Kurtosis of transitory earnings models residuals if $x_{t}=i 3 ; i \sim N[0 ; 1]$

\begin{tabular}{|c|c|c|c|c|c|c|c|c|c|c|}
\hline \multirow[t]{2}{*}{$\begin{array}{c}x_{0, t}=i^{3} \\
i \sim N[0 ; 1]\end{array}$} & \multicolumn{5}{|c|}{ Number of averaged observations in $X_{t}^{*}: 5$} & \multicolumn{5}{|c|}{ Number of averaged observations in $X_{t}^{*}: 10$} \\
\hline & $x_{0, t}$ & $\varepsilon_{(\mathrm{AR})}$ & $\varepsilon_{(5)}$ & $\varepsilon_{(6)}$ & $\varepsilon_{(7)}$ & $x_{0, t}$ & $\varepsilon_{(\mathrm{AR})}$ & $\varepsilon_{(5)}$ & $\varepsilon_{(6)}$ & $\varepsilon_{(7)}$ \\
\hline \multirow{2}{*}{$\beta=0$} & 28.252 & 28.272 & 13.850 & 48.166 & 13.850 & 27.563 & 27.561 & 13.807 & 52.487 & 13.807 \\
\hline & (5.029) & (5.039) & $(2.506)$ & (29.459) & $(2.506)$ & $(2.922)$ & (2.917) & (1.531) & (28.691) & (1.531) \\
\hline \multirow{2}{*}{$\beta=0.25$} & 26.095 & 23.252 & 12.974 & 33.802 & 12.661 & 27.908 & 24.835 & 14.620 & 48.787 & 14.004 \\
\hline & $(2.614)$ & (2.357) & (1.394) & $(26.646)$ & (1.369) & (3.167) & $(2.844)$ & (1.720) & (30.520) & (1.659) \\
\hline \multirow{2}{*}{$\beta=0.5$} & 27.626 & 18.864 & 15.084 & 37.401 & 13.602 & 28.027 & 19.278 & 17.175 & 32.823 & 14.385 \\
\hline & (3.445) & $(2.365)$ & (1.903) & (25.743) & (1.701) & (2.973) & $(2.045)$ & (1.832) & $(22.524)$ & (1.588) \\
\hline \multirow{2}{*}{$\beta=0.75$} & 29.744 & 15.976 & 18.108 & 26.610 & 14.736 & 27.677 & 14.788 & 20.300 & 14.043 & 13.677 \\
\hline & $(4.846)$ & $(2.682)$ & (3.007) & $(18.326)$ & (2.441) & (3.304) & $(1.860)$ & (2.517) & (11.934) & (1.783) \\
\hline
\end{tabular}

Average kurtosis of 100 times 1000-period time series of $x_{t}=i^{3} ; i \sim N[0 ; 1]$

Source: own research

a large enough sample to form a central tendency of the examined variable, one could also fully rely on pure MR. Pure MR model is also, together with Lev's (1969) PA model, the most robust to the leptokurtic distribution of the examined time series, although not fully.

The MR model differs from the formerly used AR and PA models in the way that it can distinguish steady convergence towards the mean from purely random oscillation and that the mean is not company-specific, but rather determined by the characteristics of the relevant peer group. PA models, although quite widely used for the examination of transitory earnings, provide biased estimates MR rate, especially if there is weak or no convergence towards a central tendency in the examined process.

The other findings show that the consistent and practically usable profitability and earnings measures have been researched only scarcely. Besides that, we find that the pure MR model is robust to both non-normally skewed and spiky input variables in terms of residuals normality. This property gains importance in the case of financial ratios mean reversion research, because financial ratios are rather nonnormally distributed.

All the above findings should prepare the ground for follow-up work, which intends to find on an empirical basis, whether there is any predictable pattern in companies' profits related to the industry and exploitable for their forecasting.

\section{CONCLUSION}

There is a vast number of papers on transitory earnings (and other financials or their ratios). However, few papers study transitory financials expectations as well as the methodology of transitory financials research. Given the importance of earnings forecasts for valuation of shares in companies 
as a substantial part of national wealth, theory and practice needs a tool to assess the persistence of transitory earnings. This paper proposes a model of pure mean reversion of earnings, similar to Grop's (2004) mechanical mean reversion model.

Simulation-based test of accuracy in a cyclical environment and the test of robustness to input variables non-normality show that the proposed mean reversion model is a superior choice to a simple autoregressive model and to the most commonly used partial adjustment models (Lev, 1969 or Waud, 1968) if one wants to study the transitory financials (or their ratios). Namely, we find that:

1) Lev's (1969) partial adjustment model provide biased and inaccurate estimates of abnormal earnings persistence in a cyclical environment,

2) pure AR (1) models do not portray the reversion towards industry averages well in cyclical environment and

3) the distribution of time series directly relates to the distribution of residuals in autoregressive and partial adjustment models.

\section{Acknowledgements}

This paper is the result of a research project supported by the Faculty of Economics, University of South Bohemia within the Internal grant competition [No. EF-IGS2017-Vlčková-IGS23A1, named "Transitory and Expected Earnings"].

\section{REFERENCES}

ÁRENDÁŠ, P. and CHOVANCOVÁ, B. 2015. The Adaptive Markets Hypothesis and the BRIC Share Markets. Ekonomický časopis, 63(10): 1003-1018.

BALL, R., GERAKOS, J., LINNAINMAA, J. T. and NIKOLAEV, V. V. 2015. Deflating profitability. Journal of Financial Economics, 117(2): 225-248.

BEATTY, R. P., RIFFE, S. M. and THOMPSON, R. 1999. The Method of Comparables and Tax Court Valuations of Private Firms. Accounting Horizons, 13: 177-199.

BEAVER, W. H., MCNICHOLS, M. F. and WANG, Z. Z. 2018. The information content of earnings announcements: New insights from intertemporal and cross-sectional behavior. Review of Accounting Studies, 23(1): 95-135.

BEAVER, W. H. 1970. The Time Series Behavior of Earnings. Journal of Accounting Research, 8: 62-99.

BLISS, J. H. 1923. Financial and Operating Ratios in Management. New York: The Ronald Press.

BOLDIN, M. V. and PETRIEV, M. N. 2018. On the Empirical Distribution Function of Residuals in Autoregression with Outliers and Pearson's Chi-Square Type Tests. Mathematical Methods of Statistics, 27(4): 294-311.

BRADSHAW, M. T. 2004. How Do Analysts Use Their Earnings Forecasts in Generating Stock Recommendations? The Accounting Review, 79(1): 25-50.

DECHOW, P. M., HUTTON, A. P. and SLOAN, R. G. 1999. An empirical assessment of the residual income valuation model. Journal of Accounting and Economics, 26(1-3): 1-34.

DEMIRAKOS, E. G., STRONG, N. C. and WALKER, M. 2004. What valuation models do analysts use? Accounting Horizons, 18(4): 221-240.

DICHEV, I. D. and TANG, V. W. 2009. Earnings volatility and earnings predictability. Journal of Accounting and Economics, 47(1): 160-181.

DOUKAS, J. A., KIM, C. and PANTZALIS, C. 2002. A Test of the Errors-in-Expectations Explanation of the Value/Glamour Stock Returns Performance: Evidence from Analysts' Forecasts. The Journal of Finance, 57(5): 2143-2165.

EWING, B. T. and THOMPSON, M. A. 2007. Asymmetric MR in corporate profits. Applied Economics Letters, 14: 935-938.

FAMA, E. F. and FRENCH, K. R. 2000. Forecasting Profitability and Earnings. Journal of Business, 73(2): 161-175.

FAIRFIELD, P. M., RAMNATH, S. and YOHN, T. L. 2009. Do Industry-Level Analyses Improve Forecasts of Financial Performance? Journal of Accounting Research, 47(1): 147-178.

FRANKEL, R. and LITOV, L. 2009. Earnings persistence. Journal of Accounting and Economics, 47(1): 182-190.

FRECKA, T. J. and LEE, C. F. 1986. Generalized Financial Ratio Adjustment Processes and Their Implications. Journal of Accounting Research, 21(1): 308-316.

GODDARD, J., TAVAKOLI, M. and WILSON, J. O. 2005. Determinants of profitability in European manufacturing and services: evidence from a dynamic panel model. Applied Financial Economics, 15(18): 1269-1282. 
GORDON, M. J. 1959. Dividends, earnings, and stock prices. The Review of Economics and Statistics, 49(2): 99-105.

GROPP, J. 2004. MR of industry stock returns in the US, 1926-1998. Journal of Empirical Finance, 11: 537-551.

HERRMANN, V. and RICHTER, F. 2003. Pricing with performance-controlled multiples. Schmalenbach Business Review, 55(3): 194-219.

IOANNIDIS, C., PEEL, D. A. and PEEL, M. J. 2003. The time series properties of financial ratios: Lev revisited. Journal of Business Finance \& Accounting, 30(5-6): 699-714.

KONINGS, J. and ROODHOOFT, F. 1997. Financial ratio cross-section dynamics: A non-parametric approach. Journal of Business and Accounting, 29(9-10): 1331-1342.

LEV, B. 1969. Industry Averages as Targets for Financial Ratios. Journal of Accounting Research, 7(2): 290-299.

NISSIM, D. and PENMAN, S. H. 2001. Ratio analysis and equity valuation: From research to practice. Review of Accounting Studies, 6(1): 109-154.

PENMAN, S. H. 1996. The articulation of price-earnings ratios and market-to-book ratios and the evaluation of growth. Journal of Accounting Research, 34(2): 235-259.

QI, H. 2011. Value and capacity of tax shields: An analysis of the slicing approach. Journal of Banking \& Finance, 35: 166-173.

SLOAN, R. G. 1996. Do stock prices fully reflect information in accruals and cash flows about future earnings? Accounting Review, 71(3): 289-315.

TONG, H. 2011. Threshold models in time series analysis-30 years on. Statistics and its Interface, 4(2): 107-118.

VLČKOVÁ, M. and BUUS, T. 2018. Impact of financial data quality on models used to describe transitory earnings. In: Economic and Social Development, $27^{\text {th }}$ International Scientific Conference on Economic and Social Development. Rome, 1-2 March 2018, pp. 746-752.

VLČKOVÁ, M. and BUUS, T. 2019. Literature Review of Transitory Earnings. In: $13^{\text {th }}$ International Scientific Conference INPROFORUM: 100 Years of the Koruna. November 7th 2019 , České Budějovice, pp. 227-231.

WAUD, R. N. 1968. Misspecification in the Partial Adjustment and Adaptive Expectations Models. International Economic Review, 9(2): 204-217.

Contact information

Miroslava Vlčková: mvlckova02@ef.jcu.cz 